\title{
Hybrid DE - HS Algorithm with Randomized Parameters
}

\author{
Rastgele Değişkenli Melez DG-HA Algoritması
}

\section{Ezgi DENIZ ÜLKER*}

European University of Lefke, Engineering Faculty, Computer Engineering Department, Mersin-10, TURKEY.

\author{
• Geliş tarihi / Received: 28.05.2018 • Düzeltilerek geliş tarihi / Received in revised form: 21.11.2018 • Kabul tarihi / Accepted: 23.11 .2018
}

\begin{abstract}
The evolutionary algorithms and their hybrid methods are quite efficient and accurate in terms of solution quality of optimization. In this study, a new hybrid algorithm is generated by merging Differential Evolution (DE) and Harmony Search Optimization (HS) algorithms which is called DES. The core steps of the algorithms are used without any modifications, but the main control parameters which directly affect the performance are randomized. The experimental study is done by comparing DE, HS and their hybrid method DES. According to the results, it is found that DES algorithm has improved the performances of original algorithms for the selected test problems.
\end{abstract}

Keywords: Differential evolution, Evolutionary algorithms, Harmony search, Hybridization, Random parameters

$\ddot{O} z$

Evrimsel algoritmalar ve onları kullanarak yaratılan melez algoritmalar optimizasyon problemlerini çözmede etkili ve doğru sonuçlar üretirler. Bu çalışmada, Diferansiyel Gelişim (DG) algoritması ve Harmoni Arama (HA) algoritması birleştirilerek yeni bir melez algoritma oluşturulmuştur. Birleştirilen algoritmaların ana basamakları herhangi bir performans yükseltme yapılmadan kullanılmıştır, ancak performans üzerinde doğrudan etkisi olduğu bilinen ana kontrol değişken değerleri için rastgele seçim yapılmıştır. Deneysel çalışma, birleştirilen DG ve HA algoritmaları ile onların oluşturduğu DES algoritması arasında yapılmıştır. Elde edilen sonuçlara göre melez algoritma DES, diğer iki algoritmaya göre daha iyi bir performans göstermiştir.

Anahtar kelimeler: Diferansiyel gelişim, Evrimsel algoritmalar, Harmoni arama, Melezleme, Rastgele değişkenler 


\section{Introduction}

In past, optimization problems were handled by researchers using large variety of algorithms (Sama et al., 2016; Ülker, 2017; 2017, Şimşek and Şimşek, 2017). Solving a complex optimization problem is quite challenging, since there are more than one design variables. Moreover, the algorithm generally focuses on finding the global optimum point, but it may be trapped into one of the local optimum points of given problems. Therefore, classical methods may not be efficient by alone for solving complex optimization problems.

Also, as it is known from No Free Lunch theorem, some optimization algorithms are quite effective for solving some problems, while ineffective for other problems or in other words there is no optimization algorithm that is able to to solve all kinds of problems (Wolpert and William, 1997). Instead of proposing new optimization methods, by using the advantages of previously introduced and proved to be effective ones can be used in the process of optimization.

Among the large variety of algorithms; DE and HS have the significant performance for solving complex problems from different areas (Qui et al., 2016; Kukkonen and Carlos, 2017). DE has distinctive attributes which provide some advantages in optimization with respect to classical methods. DE uses mutation and crossover operations to generate a new vector by using the existing ones. It uses crossover rate $(\mathrm{CR})$ and differential weight (F) as main control parameters to avoid from local optima and to explore better areas in the search space (Qui et al., 2016). Additionally, HS algorithm can produce noticeable results by using its advantages. It optimizes a problem by generating a new vector which is derived from existing ones with its control parameters. The algorithm has an easy implementation with less number of steps. Besides the remarkable advantages of DE and HS, it is studied that both of the algorithms have high parameter dependency (Tvrdik, 2006; Chen et al., 2012; Gao et al., 2015; Chellaswamy et al., 2016; Qui et al., 2016; Wang et al., 2016; Roy et al., 2016). DE and HS need to optimize their control parameters for every problem to be handled. The algorithms DE and HS are designed in a way that a balance between exploration and exploitation characteristics is attained by applying the best combinations of their control parameters. It is seen that main control parameters effect the performance of the algorithms by controlling exploration and exploitation abilities. Therefore, there is a direct link between the selection of control parameters and the convergence rate of an algorithm. In this paper, DE and HS algorithms are hybridized to solve complex optimization problems by minimizing the disadvantages which are caused by control parameters tuning. In order to observe the improvement on the performance of the hybridized DE/HS algorithm (DES), it is compared with the original algorithms that is derived from. The experimental analysis is done by performing some complex benchmark functions.

The rest of the paper is organized as follows; section 2 shows the hybrid algorithm DES with its main steps. Section 3 describes some of the complex optimization tasks and the experimental results achieved. Lastly, section 4 gives the concluding remarks of this paper.

\section{Hybrid DE/HS Algorithm (DES)}

DE algorithm is known as a metaheuristic algorithm (Storn and Price, 1997) which tries to optimize the given problem in a large search space by avoiding local optimum points. It mainly considers two control parameters differential weight $(\mathrm{F})$ and crossover rate $(\mathrm{CR})$ which have great influence on the performance of DE. HS algorithm simply mimics the process of composers, when they compose a melody in a harmony. It produces a new solution vector after considering present vectors. This feature helps HS to obtain the optimum solution at a reasonable time. However, likewise DE algorithm, HS algorithm needs to perform fine tuning of its control parameters (Geem et al., 2001; Wang et al., 2013). The performance of HS generally relies on its main control parameters which are pitch adjusting rate (par), fretwidth (fw) and harmony memory considering rate (HMCR).

Based on the facts above, it can be said that both of the algorithms can produce remarkable results, if their control parameters are optimized for each task. However, finding the best combination values of control parameters for each task is not a time efficient process. Therefore, the control parameters are optimized in the given intervals defined in the literature.

In order to have their great potentials in solving problems, both of the algorithms are merged without any modifications on their main steps in hybrid algorithm DES. Additionally, the algorithm uses an equal random selection process 
to select the steps of DE an HS. Therefore, neither DE nor HS algorithm manipulate the process of optimization by alone. There are similar methods of hybridization which considers DE and HS algorithms in literature (Chakraborty et al., 2009; Wang et al., 2009), but DES algorithm can be distinguished from the others as giving an equal chance to the main steps of the algorithms without any modifications and as randomizing main control parameters of the algorithms. It is aimed to have a hybrid DES algorithm which is not sensitive to the set of control parameters with good convergence rate. The main steps of hybridized DES algorithm are shown in Figure 1.

Selection of DE part in DES algorithm relies on 3 main functions:

$V_{i}=X_{a}+F\left(X_{b}+X_{C}\right)$

$X_{i j}=\left\{\begin{array}{r}\text { selection from candidate population, if } r_{1}<H M C R \\ \text { randomly generation of a candidate, Otherwise }\end{array}\right.$

where $r_{l}$ is a random number between (0-1) and $H M C R$ is a control parameter of $\mathrm{HS}$ in the interval [0-1].

$$
X_{i j}=\left\{\begin{array}{cc}
X_{i}+\text { rand } * f w, & \text { if } r_{2}<\text { par } \\
X_{i}, & \text { Otherwise }
\end{array}\right.
$$

where $V_{i}$ is the mutant vector and $a, b$ and $c$ are the distinct members in the population. $F$ is a control parameter for DE in the interval [0-2].

$U_{i j}= \begin{cases}V_{i j} & \text { if } r_{j} \leq C R \\ X_{i j} & \text { Otherwise }\end{cases}$

where $U_{i j}$ is the trial vector which is generated by crossover of $X_{i j}$ and $V_{i j} . \quad r_{j}$ is a uniformly distributed random number for each member in the population and $C R$ is a control parameter for DE in the interval [0-1].

$X_{i j}=\left\{\begin{array}{cc}U_{i} \text { if } & f\left(U_{i}\right) \leq f\left(X_{i}\right) \\ X_{i} \text { Otherwise }\end{array}\right.$

where $X_{i j}$ is the member which will survive for the next generation.

Selection of HS part in DES algorithm depends on 2 main functions:

where $r_{2}$ is a random number between (0-1) and $f w$ and par are the control parameters of HS in the intervals $0.01 *$ range and [0-1], respectively.

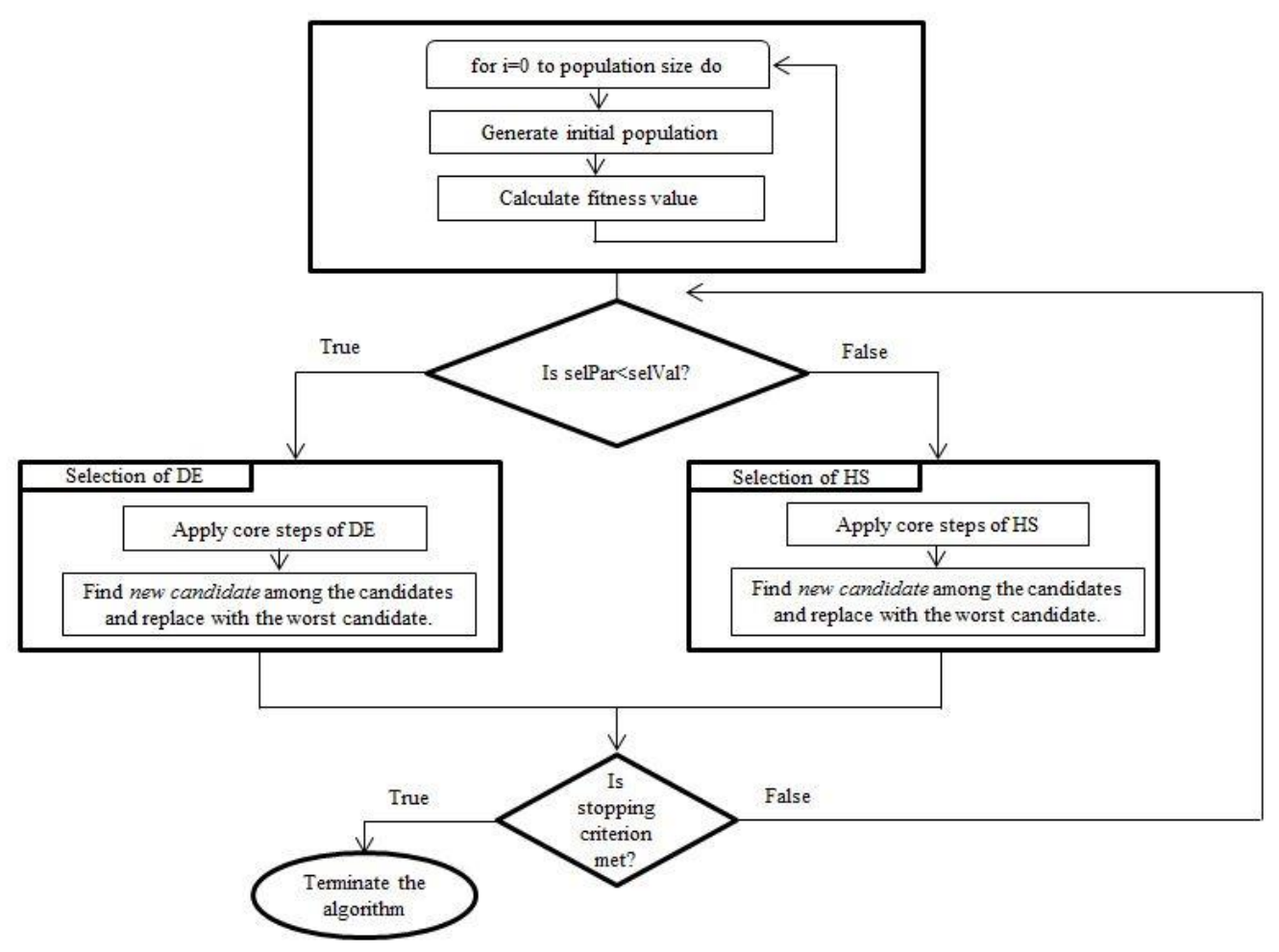

Figure 1. Main steps of hybrid DES algorithm. 
The algorithm starts by initializing the population $X$ by generating random values in the search space. Then, the selection process performed among the core steps of DE and HS algorithms. The hybrid DES algorithm gives an equal probability of selecting the steps of DE and HS. In the selection step, DES algorithm uses two selection parameters; selPar and selVal. The randomized paradigm is again considered for these control parameters. selPar and selVal are randomized in the range [0-1]. The performance of the algorithm relies on the frequency of use of the algorithms DE and HS. However, in this experiment the same chance of use is given to both of the algorithms. According to the selection done, the population is updated either by $\mathrm{DE}$ or HS at a time. Both of the algorithms uses their control parameters to obtain the global optimum value by avoiding local optimum points. The fine- tuning of these parameters is eliminated by assigning random values in predefined ranges. The algorithm repeats its steps until the stopping criterion is satisfied. At the end, the algorithm returns the optimal solution with a corresponding function value.

\section{Experimental Results and Discussions}

The hybridized algorithm DES and its originals DE and HS are compared by using some optimization problems taken from literature (Mahdavi et al., 2007). The optimization problems are selected in a way that they have multiple constraints and unknowns which show the effectiveness of the selected algorithms. The optimization problems selected for this experiment and the known optimum values are shown in Table 1 (Mahdavi et al., 2007).

Table 1. Information of test problems.

\begin{tabular}{|c|c|c|}
\hline Problem description & Problem formulation & $\begin{array}{l}\text { Optimum } \\
\text { value }\end{array}$ \\
\hline Pressure Vessel Design & $\begin{array}{c}f(x)=0.6224 x_{1} x_{3} x_{4}+1.7781 x_{2} x_{3}{ }^{2} \\
+3.1661 x_{1}^{2} x_{4} \\
+19.84 x_{1}{ }^{2} x_{3} \\
g_{1}(x)=-x_{1}+0.0193 x_{3} \leq 0 \\
g_{2}(x)=-x_{2}+0.00954 x_{3} \leq 0 \\
g_{3}(x)=-\pi x_{3}{ }^{2} x_{4}-\frac{4}{3} \pi x_{3}{ }^{3} \\
+1296000 \leq 0 \\
g_{4}(x)=x_{4}-240 \leq 0\end{array}$ & 5849.76169 \\
\hline Constrained function $\mathrm{V}$ & $\begin{array}{c}f(x)=\left(x_{1}{ }^{2}+x_{2}-11\right)^{2} \\
+\left(x_{1}+x_{2}{ }^{2}-7\right)^{2} \\
g_{1}(x)=4.84-\left(x_{1}-0.005\right)^{2} \\
-\left(x_{2}-2.5\right)^{2} \geq 0 \\
g_{2}(x)=x_{1}{ }^{2}+\left(x_{2}-2.5\right)^{2}-4.84 \geq 0 \\
0 \leq x_{1} \leq 6, \quad 0 \leq x_{2} \leq 6\end{array}$ & 13.590841 \\
\hline Unconstrained function I & $\begin{array}{r}f(x)=\exp \left\{\frac{1}{2}\left(x_{1}{ }^{2}+x_{2}{ }^{2}-25\right)^{2}\right\} \\
+\sin ^{4}\left(4 x_{1}-3 x_{2}\right) \\
+\frac{1}{2}\left(2 x_{1}+x_{2}-10\right)\end{array}$ & 1.0000 \\
\hline
\end{tabular}

For all of the algorithms in this experiment, the random values are assigned to the control parameters between the predefined intervals in each iteration found in the literature. The population size and dimension are fixed to 100 and 50. The maximum number of iterations is selected as a stopping criterion and is assigned to 500,000 for each algorithm. The results are tabulated in Table 2 which are averaged over 30 trials. 
Table 2. A comparative table obtained by DES and its originals.

\begin{tabular}{llll}
\hline Problem description & DES & DE & HS \\
\hline Pressure Vessel Design & 5997.7542 & 6112.1128 & 6349.3427 \\
Constrained function V & 13.590843 & 13.591062 & 13.590950 \\
Unconstrained function I & 1.000 & 0.99998 & 0.99997 \\
\hline
\end{tabular}

For the first problem, it is aimed to minimize the objective function by considering four design variables; $x_{1}, x_{2}, x_{3}$ and $x_{4}$, four constraints; $g_{1}(x)$, $g_{2}(x), g_{3}(x)$ and $g_{4}(x)$. Due to the complexity of this test function, the results obtained by the originals are slightly far from the global optimum value. However, using the advantages of originals together in DES provides better result. According to the best $f(x)$ value; the values for $x$ [0.8036, $0.3972,41.6392,182.4120]$ and the $g(x)$ values $[3.65 \mathrm{E}-05,3.79 \mathrm{E}-05,-1.5914,-57.5879]$ are obtained.

For the second problem, the objective function is needed to be minimized with two design variables; $x_{1}$ and $x_{2}$, two constraints; $g_{l}(x)$ and $g_{2}(x)$, and also four boundary conditions. The problem can be stated as complex because of the presence of constraints. According to the best $f(x)$ value; the values for $x[2.25,2.38]$ and the $g(x)$ values $[0.00,0.22]$ are obtained. All of the algorithms approached to the optimum value of the given problem, but it is seen that the hybrid algorithm DES has more precise value of objective function than the others.

For the third problem, the objective function has two design variables $x_{1}$ and $x_{2}$ without any constraints. The original algorithms DE and HS find the global optimum value of given problem, but in terms of accuracy DES algorithm provides a better solution than the originals. According to the best $f(x)$ value; the values for $x[3.00,3.99]$ are obtained.

\section{Conclusions}

The paper has presented a hybridized version of DE and HS algorithms which has an advantage over the originals in terms of solution quality. The control parameters have strong impacts on the performance of the algorithms. In hybridized algorithm DES, it is aimed to reduce undesirable effects that are directly related to the selecting or tuning the control parameters. On the other hand, DES does not underestimate the positive effects of control parameters in terms of exploration and exploitation characteristics of an algorithm. Therefore, the control parameters are not neglected both in the originals and their hybrid version DES. The hybrid algorithm DES can be differentiated from the other hybridization techniques by randomizing control parameters and by giving an equal chance to the originals in merging process without altering them.

The original algorithms and hybrid DES algorithm are compared for some test functions. DES algorithm achieves efficient results as well as its originals in finding global optimum by using its main control parameters. However, in terms of solution quality the results by DES are more efficient and accurate for the selected test functions. As a future work, different probability values of selecting original algorithms can be studied and the effects can be obtained on the performance of DES.

\section{References}

Chakraborty, P., Roy, G.G., Das, S., Jain, D. and Abraham, A., 2009. An Improved Harmony Search Algorithm with Differential Mutation Operator, Fundamenta Informaticae, 95, 401-426.

Chellaswamy, C. and Ramesh, R., 2016. Parameter Extraction of Solar Cell Models Based on Adaptive Differential Evolution Algorithm, Renewable Energy, 97, 823837.

Chen, J., Pan, Q.K. and Li, J.Q., 2012. Harmony Search Algorithm with Dynamic Control Parameters, Applied Mathematics and Computation, 219, 592-604.

Delice, Y., Aydoğan, E.K., Özcan, U. and İlkay, M.S., 2017. A Modified Particle Swarm Optimization Algorithm to Mixed-Model Two-sided Assembly Line Balancing, Journal of Intelligent Manufacturing, 28, 23-36.

Gao, X.Z., Govindasamy, V., Xu, H., Wang, X. and Zenger, K., 2015. Harmony Search Method: Theory and Applications, Computational Intelligence and Neuroscience,1-10.

Geem, Z.W., Kim, J.H. and Loganathan, G.V, 2001. A New Heuristic Optimization Algorithm: Harmony search, Simulation, 76, 60-68. 
Kukkonen, S.and Carlos, A.C., 2017. Generalized Differential Evolution for Numerical and Evolutionary Optimization, Springer International Publishing, 253-279.

Mahdavi, M., Fesanghary, M.and Damangir, E., 2007. An Improved Harmony Search Algorithm for Solving Optimization Problems, Applied mathematics and computation, 188, 1567-1579.

Qui, X., Xu, J.K., Tan, K.C. and Abbas, H.A., 2016. Adaptive Cross-Generation Differential Evolution Operators for Multiobjective Optimization", IEEE Transactions on Evolutionary Computation, 20, 232-244.

Roy, N., Ghosh, A.and Sanyal, K., 2016. Normal Boundary Intersection Based Multiobjective Harmony Search Algorithm for Environmental Economic Load Dispatch problem, IEEE International Conference on Power Systems, 1-6.

Sama, M., Pellegrini, I, P., D'ariana, A., Rodriguez, J. and Pacciarelli, D., 2016. Ant Colony Optimization for the Real-Time Train Routing Selection Problem, Transportation Research Part B: Methodological, 85, 89-108.

Storn, R. and Price, K., 1997. Differential Evolution-A Simple and Efficient Heuristic for Global Optimization Over Continuous Spaces", Journal of global optimization, 11, 341-359.

Şimşek, B. and Şimşek E.H., 2017. Assessment and Optimization of Thermal and Fluidity
Properties of High Strength Concrete via Genetic Algorithm, An international journal of optimization and Control: Theories\&Applications (IJOCTA), 7,90 97.

Tvrdik, J., 2006. Competitive Differential Evolution and Genetic Algorithm in GADS Toolbox, Technical Computing Prague, Praha, Humusoft, 99-106.

Ülker, E.D., 2017. A PSO/HS Based Algorithm for Optimization Tasks, IEEE Xplore Computing Conference Proceedings 2017, London, 117-120.

Ülker, E.D., 2018. An Elitist Approach for Solving the Traveling Salesman Problem using an Animal Migration Optimization Algorithm, Turkish Journal of Electrical Engineering \& Computer Sciences, 1, 605617.

Wang, G.G., Gandomi, A.H., Zhao, X. and Chu, H.C.E., 2016. Hybridizing Harmony Search Algorithm with Cuckoo Search for Global Numerical Optimization, Soft Computing, 20, 273-285.

Wang, L. and Lingp-Po, L., 2013. An Effective Differential Harmony Search Algorithm for the Solving Non-convex Economic Load Dispatch Problems, International Journal of Electrical Power \& Energy Systems, 44, 832-843.

Wolpert, D.H. and William, G. M., 1997. No Free Lunch Theorems for Optimization,1997, IEEE Transactions on Evolutionary Computation, 1, 67-87. 